\title{
Shared emotions: a Steinian proposal
}

\author{
Gerhard Thonhauser ${ }^{1,2}$ (D)
}

Published online: 8 February 2018

C The Author(s) 2018. This article is an open access publication

\begin{abstract}
The aim of this paper is to clarify the notion of shared emotion. After contextualizing this notion within the broader research landscape on collective affective intentionality, I suggest that we reserve the term shared emotion to an affective experience that is phenomenologically and functionally ours: we experience it together as our emotion, and it is also constitutively not mine and yours, but ours. I focus on the three approaches that have dominated the philosophical discussion on shared emotions: cognitivist accounts, concern-based accounts, and phenomenological fusion accounts. After identifying strengths and weaknesses of these approaches and summarizing the elements that a multifaceted theory of shared emotions requires, I turn to the work of the early phenomenologist Edith Stein to further advance an approach to shared emotions that combines the main strengths of Helm and Salmela's concern-based accounts and Schmid's phenomenological fusion account. According to this proposal, the sharedness of a shared emotion cannot be located in one element, but rather consists in a complex of interrelated features.
\end{abstract}

Keywords Shared emotions · Collective emotions · Affective intentionality · Communal experience $\cdot$ Edith Stein

The last decade has seen an emerging debate about the possibility and nature of shared or collective emotions. ${ }^{1}$ As yet, however, there has been no agreement over precisely what these labels refer to. The aim of this paper is to clarify the notion of shared emotions. Following a preliminary definition, which contextualizes the debate on shared emotions within the broader research landscape on collective affective intentionality, I will discuss three major approaches to shared emotions in contemporary philosophical debate. After identifying shortcomings in these approaches and

${ }^{1}$ For an overview of this interdisciplinary research field, see (Salmela and von Scheve 2014).

Gerhard Thonhauser

gerhard.thonhauser@univie.ac.at

1 Institute of Philosophy, Free University Berlin, Habelschwerdter Allee 30, 14195 Berlin, Germany

2 Department of Philosophy, University of Vienna, Universitätsstraße 7, 1010 Vienna, Austria 
summarizing the elements that need to be accounted for in a multifaceted theory of shared emotions, I will turn to Edith Stein to introduce several suggestions from early phenomenology that can improve current theorizing on shared emotions.

\section{Emotional sharing}

The notion of sharing is ambiguous and has been used in a number of ways with regard to various forms of affective experiences. ${ }^{2}$ To begin with, some speak of emotional sharing when an emotion is expressed by one person and perceived by another (Michael 2011). ${ }^{3}$ This has been widely discussed under the labels "social cognition" or "empathy". Considering the intentional structure of empathy, insights from early phenomenology allow us to draw a clear distinction between empathizing and sharing. In empathy, the emotion one perceives is given as the emotion of the other. Thus, when I perceive the emotion of another, I am not experiencing the same or a similar emotion. Rather, I understand the emotion as the emotion of the other, without partaking in the foreign emotion (Scheler 2008, 8-11; Stein 1989, 14-18). In contrast, sharing an emotion would imply that several individuals experience the same emotion. Second, emotional sharing can be understood as sympathizing with the emotion of another. In his classic The Theory of Moral Sentiments, Adam Smith (2002) pointed to the importance of "fellow-feeling" for moral sentiments and prosocial attitudes. The main idea is that reciprocal awareness of sympathy leads to a correspondence of sentiments, generating an affective attunement between people that is a source of pleasure (Sugden 2002). Similar to the case of empathy, the phenomenological accounts of Scheler and Stein suggest drawing a distinction between fellow-feeling and sharing. They characterize the intentional structure of fellow-feeling as empathy plus an emotional reaction to the other's emotion through an emotion of one's own. Following this analysis, it can be emphasized that fellow-feeling does not involve actual sharing, as the emotion of the other and my emotion are two separate emotions (Scheler 2008, 8-11; Stein 1989, 14-18).

Third, in sociological theory, collective emotions have recently been defined as "the synchronous convergence in affective responding across individuals towards a specific event and object" (von Scheve and Ismer 2013, 1). Even though we can rightfully say

\footnotetext{
${ }^{2}$ I use affective experience as an umbrella term for various types of affective attitudes. The philosophical debate on shared emotions has been focused on emotions proper, that is, evaluative responses to particular objects and events that immediately motivate the subject to act in accordance with their evaluative content. Little attention has been paid to the possible sharedness of other types of affective experience like moods, sentiments, or existential feelings. In this paper, I will follow the current debate and restrict myself to talking about emotions. I would like to emphasize, however, that I do not want to commit to any sharp demarcation between different types of affective experience. I am interested in the forms of sharing, not the types of affective attitudes that are shared. Over the course of the paper, the notion of "feeling" will also play a role. In current debate, a feeling is usually understood as the part of an emotion that is bodily and/or intentionally felt. Classic phenomenology, to which I will refer when drawing on Stein in the last part of the paper, mostly used the German term "Gefühl." The various connotations of Gefühl differ from those of feeling, and the term is used more like another umbrella term for different forms of affective experiences.

${ }^{3}$ Michael offers the following definition: "Shared emotions are defined for the purposes of this paper as affective states that fulfill two minimal criteria: (a) they are expressed (verbally or otherwise) by one person; and (b) the expression is perceived (consciously or unconsciously) by another person." (Michael 2011, 355)
} 
that this is a form of sharing, I want to argue that this may not be sufficient as a definition of genuinely shared emotions, as these criteria are also met when several individuals are incidentally having the same type of emotion towards the same object or event. In order to be able to draw a distinction between parallel individual emotions and shared emotions, it is sensible to say that a genuinely shared emotion requires that we share the same emotion; we do not feel it as mine and yours, but as ours. Forth, the sharing in question can be associated with what Thomas Fuchs, following Daniel Stern (1998), calls interaffectivity. Fuchs' claim is that "emotions or affects are not inner states that we experience only individually or that we have to decode in others, but primarily shared states that we experience through mutual intercorporeal affection." (Fuchs 2013, 223) There are a number of approaches that emphasize the relationality of our affective lives and thereby overcome the idea of emotions as inner states closed off from others. ${ }^{4}$ The main idea is that we are bodily connected to others in such a way that we immediately affect them, and they immediately affect us. ${ }^{5}$

What I would like to discuss as shared emotion builds on the relationality of affectivity, but concerns something more specific. I suggest that we reserve the term shared emotion for an affective experience that is phenomenologically and functionally ours: we experience it together as our emotion, and it is constitutively neither mine, nor yours, but ours.

In this paper, I will focus on recent philosophical accounts of shared emotions. The philosophical discussion has been dominated by three approaches: cognitivist accounts; concern-based accounts; and phenomenological fusion accounts. While I am critical of cognitivist accounts based on general reasons pertaining to the nature and status of affective intentionality, I think that concern-based accounts and phenomenological fusion accounts make important contributions to an adequate understanding of shared emotions. There is still work to be done, however, in the attempt to describe and comprehend the complexity of shared affectivity. I will draw on as yet underappreciated work in early phenomenology, especially the original analyses of Edith Stein, to combine concern-based accounts and phenomenological fusion accounts into a multifaceted approach to shared emotions. ${ }^{6}$ The suggested approach has the main

\footnotetext{
${ }^{4}$ Theories that emphasize the essentially relational nature of affectivity can be found in a range of sources as diverse as phenomenology (Fuchs and De Jaegher 2009), developmental psychology (Stern 1998), social psychology (Hatfield et al. 1994), and affect studies (Mühlhoff 2015).

${ }^{5}$ Some have seen the link between feelings and the body as a reason for rejecting the very possibility of shared emotions. Connor, for instance, suggests that a shared emotion would need to be "lodged in a group body" (Connor 2013, 2). It is thus crucial for an account of affective sharing to argue against a misguided ontology of the body. I take the findings of Fuchs and others to show that our embodiment does not close us off from each other, but rather makes us receptive to one another and thus enables us to feel together. Early phenomenology provides powerful resources for challenging the presumption of the physicality of the body, which seems to underlie an individualist approach to feelings (to be discussed in the following section). According to Stein, we primarily experience the body of the other not as a physical object, but as a field of expressions; in and through the expressive qualities of her body we directly encounter the other's emotions (Stein 1989, 51-54). In this paper, I leave the important issue of embodiment aside in order to focus on other aspects of the debate on shared emotions.

${ }^{6} \mathrm{My}$ aim is thus not to provide a comprehensive portrayal of Stein's theory, but to take up certain ideas from her work in order to solve systematic problems that have surfaced within current debate. Stein's possible contribution to current debates on social cognition and collective intentionality has only recently received scholarly attention. For more elaborate discussions of her work, see (Calcagno 2014; Szanto and Moran 2015b).
} 
implication that the sharedness of shared emotions cannot be located in one element, but rather consists in a complex of interrelated features of shared affective experience.

\section{Received accounts of shared emotions}

Affective sharing has only recently become an issue in research on emotions. The reason for this appears to be a deep-rooted intuition, which is shared by cognitivists (Kenny 1963; Solomon 1993) and somatic theorists (Damásio 1994; Prinz 2004) alike: namely, individualism about feelings. ${ }^{7}$ According to this view, feelings are individual states that belong to the inner mental lives of individuals. This is associated with the specific way in which feelings are linked to the body - each feels them in her own body. ${ }^{8}$ As a consequence, each of us has access only to her own feelings.

If individualism about feelings is true, it appears doubtful whether something like a genuinely shared emotion can exist. ${ }^{9}$ A theory of shared emotions thus faces a serious challenge: "The problem is whether or not we can provide a plausible account of 'straightforwardly shared' emotions without compromising our intuitions about the individualism of emotions." (Salmela 2012, 33) In what follows, I will discuss three approaches within the philosophical debate on collective emotions that take different paths in dealing with this challenge.

\subsection{Cognitivist accounts}

Gilbert $(2002,2014)$ offered the first prominent account of collective emotions, focusing on collective guilt. Her account is based on strong cognitivism about emotions, according to which an emotion is essentially an evaluative judgment. Feelings (as bodily states) usually accompany the evaluative judgment, but are not necessary for an emotion. Accordingly, what is shared in a collective emotion is not a feeling, but the evaluative judgment. It is contingent whether feeling sensations are realized in the partaking individuals, as they are not constitutive elements of the collective emotion. Insofar as emotions have an action tendency (the emotion of guilt, for instance, motivates us to apologize or redress the harm), a collective emotion is also constituted by a shared intention. Thus, what is shared in a collective emotion is a cognitive state

\footnotetext{
${ }^{7}$ In his seminal text on shared emotions, Schmid distinguished three versions of individualism about feelings: ontological; epistemological; and physical. "First, feelings are ontologically individual. (Feelings are conscious states. As such, they are ontologically subjective, i.e. somebody's feelings, and there seem to be no conscious subjects other than individual beings.) Second, feelings are epistemically individual. (If it is true that only individuals can have feelings, it is also true that individuals can have only their own feelings.) Third, feelings are, it seems, physically individual. (If it is true that individuals can have only their own feelings, it also seems to be true that individuals experience their feelings as localized in their own bodies. This seems to force us to individualize feelings in the exact same sense as bodies; under normal circumstances, however, the only bodies there seem to be are the individuals'.)" (Schmid 2009, 70)

${ }^{8}$ In a recent paper, Schmid (2015) identifies two lines of thought that support individualism about feelings and reject the possibility of genuinely shared emotions. One is linked to the role of consciousness, the other to the role of the body.

${ }^{9}$ In this paper, I will not directly discuss challenges to individualism about feelings. A phenomenology of embodiment that focuses on interaffectivity (Fuchs and De Jaegher 2009), intercorporeality (Merleau-Ponty 2012; cf. Krueger 2013), and the psychophysically neutral expressive field of the lived body (Scheler 2008) might provide the basis for such a challenge.
} 
(an evaluative judgment) and a conative state (an intention). Gilbert's cognitivist approach sidesteps the problem of individualism about feelings: Rather than a shared feeling, she understands a collective emotion as a joint commitment to an evaluative judgment, accompanied by a joint intention to the action that is implicated by this judgment. With this definition of collective emotions, Gilbert draws a straightforward analogy to her account of joint action. As such, she implicitly suggests that collective emotions are yet another application of her general theory of collective intentionality.

Konzelmann Ziv has pointed out that it remains unclear how Gilbert can distinguish the feeling of guilt from judging that one is liable for a wrong. On Gilbert's account, feeling sensations cannot play this role, but it remains a mystery as to what other element can account for this distinction (Konzelmann Ziv 2007, 481): "Gilbert's analysis of collective guilt feeling appears to be rather an analysis of collective belief than an analysis of collective emotion. If the constitutive element of an emotion is understood as an evaluative judgment, and if judgments or beliefs can be ascribed to collectives, then a theory of collective belief seems sufficient to account for collective emotion. "(Konzelmann Ziv 2007, 483) Similarly, Salmela critically notes that "a joint commitment to feel amounts to the creation of a feeling rule rather than to an emotion", adding that it appears "implausible that we can commit ourselves to an emotion" (Salmela 2012).

These points refer to a general issue with cognitivist accounts, namely the "problem of emotionality" (Helm 2001, 38), which can be formulated in the following question: If an affective state is not affective to begin with, how can it ever become affective? In response to this problem, several authors have taken what we might call a phenomenological turn in the philosophy of emotion (Goldie 2000; Helm 2001; Ratcliffe 2008; Slaby 2008; Slaby et al. 2011; Schmid 2014b, 2016; Demmerling 2014). Their main claim is that in the case of affective intentionality, the intentional and the phenomenal aspects of a mental state or episode cannot be separated. According to this view, the general problem with cognitivist solutions to emotional sharing is that they fail to establish how what they term a collective emotion can ever be an affective state (and not a mere aggregate of cognitive and conative states), since they separate the intentional element (the evaluative judgment) from the phenomenal element (the felt experience) in a way that makes it impossible to account for the distinction between a judgment and an emotion. ${ }^{10}$

\footnotetext{
${ }^{10}$ Another approach to collective emotions is Huebner's (2011) functionalist account that understands emotions within the theory of computational systems. According to Huebner's view, "emotions can be exhaustively characterized in terms of the representational and computational processes that we find in a hierarchically organized and highly distributed system" (Huebner 2011, 101). Huebner first discusses the example of the navy vessel USS Palau. He describes the responses of the crew members (in interaction with the technical equipment of the ship) to an engine failure of the fast-moving ship that creates the imminent danger of running aground. Huebner suggests that the interplay of various processes that enable the detection of and appropriate response to the danger display a similar degree of sophistication as an instance of collective fear. However, he ultimately rejects the USS Palau as an example of collective fear as he observes a lack of "the sort of agitation that we find in the case of a fear representation" (Huebner 2011, 114). He then presents the closing days of the McCain-Palin campaign in 2008, when the campaign realized that it was losing, as an example of a system that possesses enough complexity to represent fear. I submit that functionalist accounts like Huebner's also face the "problem of emotionality."
} 


\subsection{Concern-based accounts}

The solution to the problem of emotionality is to define emotions as felt evaluations; they are at once evaluations and feelings (Helm 2001, 2002, 2009). Following Kenny (1963, 195), Helm distinguishes the target of an emotion from its formal object. An emotion is not simply directed at an object; rather, it attributes an evaluation to that object. Each type of emotion corresponds with a formal object, distinguishing it from other types. Moreover, Helm adds a third element to the analysis of an emotion: its focus. The focus of an emotion denotes "the background object having import to the subject that makes intelligible the evaluation implicit in the emotion." (Helm 2001, 69) Import is a technical term introduced by Helm, signifying the "worthiness imparted by a subject's concern for something" (Helm 2001, 32). To give an example: If I am afraid that the ball with which the kids next door are playing is going to damage my garden gnome, the ball is the target of my fear, which I evaluate as dangerous (formal object), because I am concerned (import) about the structural integrity of my garden gnome (focus).

Emotions play an important role in the life of a person, as they reveal what is important to her. When experiencing an emotion, a person is at once aware of the situation and her own concerns (Slaby 2008, 139). Moreover, emotions both disclose and constitute our evaluative perspective. Emotions are characterized by a certain passivity which makes them similar to perceptions: "The capacity for emotion is a kind of receptivity to evaluative content, and particular emotions are passive exercises of that receptivity." (Helm 2002, 16) However, the relation of an emotion to its object is not identical to that of a perception, "for import is relative to the individual: it is constituted by our cares and concerns." (Helm 2002, 16) Import not only forms the basis for emotional responses, but also depends on our emotions; if someone would constantly fail to show adequate emotional responses when an object is affected, we would not say that this object has import to her. "In short, import is both objective, as rationally prior to particular emotions, and subjective, as conceptually dependent on the shape of one's emotions generally."11 (Helm 2002, 16) Furthermore, an emotion commits a person to the import of its focus and target. For instance, if I am afraid when the ball approaches my garden gnome, I should also be relieved when it misses it otherwise it would be hard to comprehend the import that the garden gnome has for me. Our emotions form a pattern that allows us to make sense of the way in which things matter to us. The specific pattern of emotions is what constitutes a person's evaluative perspective.

In later work, Helm $(2008,2014)$ applied his account of emotions as felt evaluations to the case of group agents. He begins by introducing a distinction between a plural robust agent and a plural intentional system. Plural intentional systems might have collective beliefs and collective intentions enabling them to act as a unit, but they are not plural agents in a robust sense. For a group to be a plural robust agent, it must be a subject of import with a corresponding pattern of emotions. A plural robust agent has its own evaluative perspective that is shared among its members. The members of a plural robust agent are responsive to what has import to $u s$; they feel emotions as one of us, as part of the group.

\footnotetext{
${ }^{11}$ Emotions do not fit into the classic belief-desire-model of intentionality. They have neither the mind-toworld direction of fit of belief, nor the world-to-mind direction of fit of desire; or, if one prefers, they have both directions of fit. It becomes clear that "direction of fit" does not contribute to our understanding of emotions (Schmid 2009, 62 f.) As a consequence, emotions (or, rather, affective states more generally) should be seen as a class of mental phenomena sui generis.
} 
Helm (2008) offers the following explanation: Members care about what the group does as part of caring about the group itself as an agent. As members of a group, we respond to the unified evaluative perspective because we care about us as a plural agent. The evaluative perspective of the group is both shared and constituted by us. On the one hand, the unified evaluative perspective depends on the emotions of the members. On the other, the members are committed to the evaluative perspective of the group. As a consequence, members of a plural agent must also share an understanding of which individuals constitute this plural agent. Being a member of a plural agent means to criticize and be criticized from the evaluative perspective of the group. ${ }^{12}$

In a certain sense, Helm's account has the same strength or weakness - depending on one's perspective - as the cognitivist solution. In short, a collective emotion in his sense does not seem to involve any sharing of feelings. What is shared among the members of a plural agent is the underlying evaluative perspective, not the affective experience. The problem with this account is that it is also fulfilled by parallel individual emotions, as long as they are based on the same underlying evaluative perspective. Helm's theory does not allow us to differentiate between cases of parallel group-based emotions and cases in which an emotional episode is presently shared. The counter-intuition is that for an emotion to be genuinely shared, not only the underlying import, but also the affective experience must be shared. ${ }^{13}$

The concern-based account of shared emotions advanced by Salmela responds to this challenge (Salmela 2012; Salmela and Nagatsu 2016, 2017). Salmela agrees with Helm in suggesting that shared emotions are based on the involved individuals sharing the relevant emotional appraisal structures. Following Roberts (2003), he develops this through the notion of "concern": "Concerns psychologically underlie emotions as perceived changes in their status evoke emotions about the perceived cause of those changes in the agent whose concern is affected favorably or adversely." (Salmela 2012,39) In contrast to Helm, Salmela notes that for a shared emotion, it is not sufficient that the involved individuals share the underlying concern; they must also share the affective experience. ${ }^{14}$

\footnotetext{
12 This explains the specific normativity inherent in collective emotions. I will briefly touch upon this aspect again in section 3.1 .

${ }^{13}$ Some disagree with this intuition. Sánchez Guerrero, for instance, affirms that when we share an emotion, this actually means that we share the underlying import in such a way that it is a similar basis for our individual emotions (Sánchez Guerrero 2011; cf. also Demmerling 2014). He states this in a critical discussion of Schmid's (2008) phenomenological fusion account. Sánchez Guerrero claims that the issue of collective emotions is about understanding how we can feel something together, rather than explaining how we can share a feeling-sensation (Sánchez Guerrero 2011, 280). In his view, feeling something together is best explained in terms of the sharedness of an underlying concern.

${ }^{14}$ Salmela's account also allows for distinctions to be made between various degrees of sharing. He claims that the "collectivity of emotions should be understood as a continuum rather than as an on/off question." (Salmela and Nagatsu 2016, 36) According to Salmela, both the sharing of the evaluative content and the sharing of the affective experience allow for degrees. Regarding the evaluative content, Salmela introduces a typology of shared concern: from overlapping private concerns, to socially grounded concerns based on mutual awareness, and finally to collective concerns based on the collective commitment of the members of the group (Salmela 2012, 39 f.). These types of shared concern are the basis for distinguishing "weakly, moderately, and strongly shared emotions." (Salmela 2012, 42) Regarding the affective experience, we can distinguish between various degrees of affective synchronization in respect of the various constituents of an emotion (Salmela and Nagatsu 2016, 2017). I agree with Salmela and Nagatsu (2017) that it is the task of empirical research on emotions to explore these components of the affective experience and the underlying causal processes of emotional convergence. In this paper, I argue for an integrative account of shared emotions, but my chief focus is their phenomenology, and especially the difficult question of consciousness.
} 
Salmela provides the following definition of shared emotion. An emotion is shared if two or more individuals experience "an emotion of the same type with similar (1) evaluative content and (2) affective experience", and are mutually aware of this (Salmela and Nagatsu 2016, 36). Rather than focusing exclusively on the sharedness of underlying concern, Salmela introduces three conditions for an emotion to be genuinely shared. First, a plurality of individuals needs to share the constituents of an emotion; besides the evaluative component (appraisal), this includes physiological changes, expressive behaviors, action tendencies, and subjective feelings (Salmela 2012, 42). ${ }^{15}$ Second, those individuals need to experience an emotion of the same type. Finally, there must be a mutual awareness condition for shared emotion proper.

I follow Salmela in his crucial claim that we need to account for several necessary conditions of shared emotions. Most importantly, I agree that a shared emotion requires the sharing of both the evaluative content and the affective experience by a plurality of individuals. Regarding the second condition, Salmela's requirement that the partaking individuals need to experience the same type of emotion might be too restrictive. Salmela's claim stands in contrast to Schmid who suggests that the sharing of emotions is often "a matter of the qualitative difference between the individual contributions." (Schmid 2009, 79; cf. 2014b, 12) I consider it an open question as to what degree of diversity among the experiences of the involved individuals is feasible in a shared emotion. ${ }^{16}$ Finally, I think that Salmela's mutual awareness condition is, in a certain sense, not strong enough. I consider this condition to implicitly serve the purpose of distinguishing shared emotions from group-based emotions. If we apply this distinction to Helm's account, we can see that what Helm theorizes are group-based emotions, i.e. emotions that individuals feel on the basis of their identification with a group, and not shared emotions in the sense suggested by Salmela and further developed in this paper. However, mutual awareness might not be sufficient to account for this distinction, since it could be the case that individuals are mutually aware of each other's group-based emotions, but do not experience them as shared. In section 3, I will introduce two additional requirements for shared emotions, which can better fulfill the function intended by Salmela's mutual awareness condition.

\subsection{Phenomenological fusion accounts}

For an emotion to be genuinely shared, i.e. shared in a sense that means more than the sharedness of the underlying appraisal pattern, we need to account for the sharing of affective experience. Schmid was the first to address this question head on, exploring whether there is a straightforward sense in which a feeling can be shared (Schmid 2008, 2009, 59-86).

Following the phenomenologist Max Scheler, Schmid claims that there is a straightforward sense of sharing a feeling. Scheler's famous example of such straightforward sharing, or feeling-together (Miteinanderfühlen) as he calls it, is two parents standing beside the dead body of their beloved child: "They feel in common the 'same' sorrow,

\footnotetext{
${ }^{15}$ For a component view of emotions, see (Scherer 2005).

${ }^{16}$ My hypothesis is that differences between the emotions felt by the participants can be integrated into a shared emotion as long as there remains a certain level of complementarity between them - and the other conditions for a shared emotion are fulfilled. As I briefly discuss in section 3.2., Stein makes a similar suggestion.
} 
the 'same' anguish. It is not that A feels this sorrow and B feels it also, and moreover that they both know they are feeling it. No, it is a feeling-together." (Scheler 2008, 12 f.; translation modified) Taking up another suggestion made by Scheler, Schmid distinguishes two kinds of subject of a conscious state: "The subject of a conscious state can mean either of the following: a) the subject who has the conscious state in question; b) the subject as who the subject takes himself or herself to have the state in question." (Schmid 2009, 77) Schmid's idea is to allow different subjects to take positions a) and b). He claims that this will enable us to develop a straightforward sense of sharing without violating the true intuition expressed in individualism about feelings: "Individuals can have only their own conscious states, especially feelings but this does not answer the question as who those individuals take themselves to have their conscious states ... Without doubt, the parents in Scheler's example are two different persons each of whom has his or her own feelings. But this does not preclude the possibility that both of them experience their feelings as theirs (together) rather than as separate personal feelings." (Schmid 2009, 77 f.) According to Schmid's account, a shared feeling is one affective episode with a plurality of individuals as participants. ${ }^{17}$

The most controversial aspect of Schmid's original account is his token identity claim: individuals who share an emotion experience one (token) emotion together. ${ }^{18}$ He understands this as the straightforward sense of sharing, which he illustrates with the examples of sharing a cake, sharing a bottle of wine, sharing an apartment, or sharing a car. According to Schmid, sharing a bottle of wine does not mean "that you and I each open a bottle, the two bottles being of the same vintage, or brand. Rather, I suggest that we enjoy one and the same (token) bottle. ... The idea is this: one car, many users, one cake, many pieces, one apartment, many inhabitants, and so on, and so forth." (Schmid 2009, 69) These seemingly straightforward examples, however, lead to a problem. In all of Schmid's examples, to share something means to distribute it. Sharing a cake entails dividing it by the number of individuals who want a piece. As a consequence, if we share a cake, each individual only enjoys her piece. Moreover, if more people participate, the pieces become smaller. This is obviously an implausible analogy for affective sharing: my part of a feeling does not diminish if I share it with more people; if this were the case, then episodes of collective feelings in large gatherings would be implausible. More importantly, each individual enjoying only her piece is exactly the opposite of what Schmid aims at. In a later paper, Schmid acknowledges this problem and explains that we need a notion of sharing that is of the participatory rather than the distributive kind, "in which participation does not dissolve, but rather strengthens the whole to which the parts are parts." (Schmid 2014b, 12 f.) This, however, is begging the question. Regarding the example of the apartment, I agree that there is a sense in which it is

\footnotetext{
${ }^{17}$ For other insightful readings of Scheler's category of feeling-together, see (Krebs 2010; Schloßberger 2016). Krebs explicitly rejects Schmid's token identity claim and draws on Stein to offer an alternative interpretation of the grieving parents. My suggestion in the last part of the paper slightly differs from her interpretation: Krebs locates the criterion for feeling-together in the content of the experience; together with the "intention toward the communal experience" (Stein 2000, 137), which Krebs interprets as a kind of mutual awareness and interaction condition. In his convincing interpretation, Schloßberger stresses the importance of "intentional feeling" - feeling (Fühlen) as distinct from feelings (Gefühl) - in Scheler. This category has largely been ignored in other recent scholarship on Scheler. I implicitly build on Schloßberger's idea that we can feel together because intentional feeling directly shows itself in expressive behavior.

${ }^{18}$ For a recent critique of the token identity claim, see (León et al. 2017, 7-10).
} 
meaningful to say that a person living in a shared apartment inhabits the whole apartment, and not only her room and parts of the common area. Nevertheless, there is also a sense in which the example remains one of distributive sharing: The space of the apartment gets distributed among the inhabitants, and if more people move in, the space allocated to each individual gets smaller. Hence, the example still does not offer a plausible image of participatory sharing that can serve as an illuminating analogy for shared emotions.

I take the general problem with these examples to be that there is an essential disanalogy between the sharing of physical objects and the sharing of (affective) mental states. Whereas we have a clear sense of the way in which a token of a physical object gets shared - in which case sharing always involves some form of distribution - this image is ill-suited to serve as a model for understanding sharing in the domain of affective experiences, and most likely mental states in general. Although I am sympathetic to Schmid's idea that shared emotions require a form of participatory sharing, I consider his token identity claim to be incapable of cashing this out.

\subsection{Towards a multifaceted account of shared emotions}

Based on the discussions of Helm and Salmela's concern-based accounts and Schmid's phenomenological fusion account, I want to suggest that our notion of shared emotion should contain the following features. To begin with, I agree with Salmela that a shared emotion entails the sharing of two constitutive elements: evaluative content and affective experience. The sharing of evaluative content can be spelled out in terms of the collectivity of the underlying appraisal pattern. Helm offers the most advanced theory to address this task. Following Schmid, we see that a theory of shared emotions also needs to include a plausible notion of the sharing of affective experiences to be able to distinguish genuinely shared emotions from parallel individual emotions and group-based emotions.

In addition to emphasizing these two elements of a shared emotion, I follow Szanto (2016, 161) and León et al. $(2017,13)$ in suggesting two complementary requirements for a theory of shared emotions; requirements that are implicitly present in the discussed accounts. First, the plurality condition contends that "there must be a plurality of individuals engaged in shared emotion and an experienced differentiation between them." (León et al. 2017, 14) Second, the integration condition concerns the first-person plural character of a shared emotion; it must be experienced as our emotion.

\section{Stein's contribution to our account of shared emotions}

In this last section, I will draw on the phenomenological work of Edith Stein to elaborate on these defining features of shared emotions. The main sources for Stein's account of affective sharing are her 1917 dissertation On the Problem of Empathy (Zum Problem der Einfühlung) and her treatise "Individual and Community", published in 1922 as part of Zur philosophischen Begründung der Psychologie und der Geisteswissenschaften (published in English as Philosophy of Psychology and the Humanities). Stein's investigations are not restricted to the question of affective sharing. 
Following the debate within the early phenomenological movement, she is interested in communal experiences (Gemeinschaftserlebnisse) more generally. ${ }^{19}$

I will not offer a detailed reconstruction of Stein's theory here, but instead focus on elements of her work that enable us to advance the theorizing of the defining features of shared emotions set out in the previous section. ${ }^{20}$ Stein concurs with the view that what is shared in a shared emotion is not one element, but rather a complex of several features. In the remainder of the paper, I will discuss Stein's possible contributions to our understanding of the sharing of evaluative content (3.1) and affective experience (3.2), cashing out the latter in terms of the plurality requirement (3.2.1), and the integration requirement (3.2.2).

\subsection{Evaluative content}

In the context of the contemporary debate, the sharing of evaluative content can be accounted for in terms of the sharedness of the underlying appraisal pattern. Stein's approach is similar in this regard, although she holds theoretical commitments that distance her somewhat from the current debate. Most importantly, Stein - in line with many early phenomenologists - maintains a realist view of value. Following Scheler (1973), Stein states that affective acts (Gemütsakte) are based on feeling (Fühlen), the apprehension of an object or event in light of a value. In other words, feelings (Gefühle), what the current discourse calls emotions, are responses to the feeling of value (Stein 2000, 159). I do not think that this represents a significant divergence between Stein and current approaches: The distinction between object and value is analogous to the distinction between target and formal object of an emotion. ${ }^{21}$ The difference arises with respect to the source of normativity governing the appropriateness of an emotion.

According to Helm's theory, the normativity involved in a collective emotion stems solely from the unified evaluative perspective of the group - members are committed to the evaluative perspective of the group and can therefore be rebuked if they fail to enact the appropriate emotions. I think that Stein is in agreement with this source of normativity, as her account of collective personhood (Stein 2000, 196-201) can be seen as analogous to Helm's notion of plural robust agents. However, Stein adds a second source of normativity for an emotion, namely its appropriateness with respect to the value it discloses. As several commentators (Caminada 2015; Szanto 2015;

\footnotetext{
${ }^{19}$ Vendrell Ferran (2015), however, has shown that emotions play a crucial role in Stein's accounts of empathy and communal experience.

${ }^{20}$ For a detailed discussion of Stein's work, see the contributions to the special issue of Human Studies edited by Szanto and Moran (2015a; Taipale 2015; Vendrell Ferran 2015; Szanto 2015; Burns 2015; Caminada 2015; Jardine 2015).

${ }^{21}$ It is important to note that feelings (Gefühle) and feeling (Fühlen) are not two distinct intentional acts. Their distinction is rather the result of an abstraction achieved by phenomenological analysis. Feeling (Fühlen) can be seen as the constituent of an emotion that explains its intentional directedness and evaluative content. There is nevertheless a crucial difference. Within Helm's framework, the experience of an object or event in light of a formal object is always associated with this object having import for a subject. As a consequence, the evaluation of a target in terms of a formal object is inseparable from the experience of an emotion. In contrast, Stein's approach suggests that there can be a feeling of value without an emotional response. She bases this on a realist view of value. It remains to be investigated whether we can make sense of this distinction without having to commit to value realism. I thank an anonymous reviewer for pointing out the differences mentioned in this footnote and in the following paragraph.
} 
Vendrell Ferran 2015) have noted, Stein links this with strong realism with regard to value, according to which emotions have values as objective correlates. As a consequence, she considers emotions as objectively right or wrong evaluation of their targets. If we do not subscribe to value realism, we obviously need to drop the claim that an emotion will or will not be objectively appropriate vis-à-vis their formal object. Nevertheless, Stein's work might help us address the normative issues raised by shared emotions, many of which have yet to receive adequate attention in recent debates (Szanto 2015). I will not discuss this issue further here. Instead I will concentrate on spelling out the other features of a shared emotion.

\subsection{Affective experience}

Individualism about feelings has led a number of recent commentators to deny experiential sharing and to restrict the collectivity of shared emotions to the evaluative content. However, we have seen that the sharing of evaluative content and the underlying evaluative perspective are insufficient for distinguishing shared emotions from group-based emotions. Stein claims that even if we add the criterion of mutual awareness, we do not arrive at genuinely shared emotions (Stein 1989, 17 f.): For a shared emotion, it is not sufficient that we, each individually, experience an emotion as members of a community; we also need to experience it together. An emotional episode counts as an instance of a group-based emotion if an individual experiences the emotion as a member of a group. In the case of a shared emotion, however, two additional requirements must be met: a shared emotion requires an awareness of a plurality of partaking individuals (plurality requirement), and an awareness of ' $u s$ ' as the plural emoter (integration requirement).

Before proceeding to discuss further these two requirements, I want to mention Stein's position vis-à-vis two issues concerning the sharing of affective experience. First, Stein (2000, 136-39) suggests that when individuals share an emotion, they do not need to have the exact same experience. Depending on their individual constitution and their role in the communal experience, they might feel different elements of an emotion, or they might experience the entire emotion with various intensities. Second, Stein (2000, 145-51) suggests that bodily sensations (e.g. physical pain) are not apt to contribute to the constitution of a communal experience. Stein sets the threshold for the possibility of communal experiences where the regularity and arrangement of experience enables object-constitution (Gegenstandskonstitution). With this restriction, Stein roughly follows Scheler's (1973, 328-43) suggestion that feeling sensations (Empfindungen) cannot be shared due to their lack of intentionality and their specific relation to one's own body.

\subsubsection{Plurality condition}

Following León et al. (2017), I suggest that an account of affective sharing needs to fulfill the plurality and the integration requirements. Whereas the integration requirement implies that we experience a shared emotion as our experience, the plurality requirement indicates that more than one individual is part of that experience, and that the participants are aware of such a plurality. In this section, I will begin by discussing 
the plurality requirement via the two main examples of communal experiences provided in Stein's seminal texts. ${ }^{22}$

In On the Problem of Empathy Stein gives the following example of a shared emotion: "A special edition of the paper reports that the fortress has fallen. As we hear this, all of us are seized by one excitement, one joy, one jubilation. We all have 'the same' feeling. Have thus the barriers separating one 'I' from another broken down here? ... Not entirely. I feel my joy while I emphatically comprehend the others' and see: it is the same." (Stein 1989, 17; translation modified) With this example, Stein shows that a shared emotion presupposes empathy (Einfühlung), which she defines as "the experience of foreign consciousness in general" (Stein 1989, 11), a direct apprehension of others' mental states. Hearing about the victory (probably in a situation of joint attention), the individuals involved emphatically comprehend one another's emotional response, and sensing the similarity of those responses, their experiences merge into one: "Seeing [the other's joy], it seems that the non-primordial character of the foreign joy has vanished. Step by step, their unreal [schemenhaft] joy coincided with the joy present in my flesh [leibhaftlebendig], and theirs is just as live to them as mine is to me. Now I intuitively have before me what they feel. It comes to life in my feeling, and from the 'I' and 'you' arises the 'we' as a subject of a higher order." (Stein 1989, 17; translation modified) Stein emphasizes that while sharing an emotion implies such a merging into a subject of higher order, it does not eliminate other-awareness. A shared emotion, as a form of communal experience, requires that each of us participates as a distinct individual.

Let me clarify this with help of a fictional counter-example: the alien group Borg from the science fiction franchise Star Trek. The Borg are a collective of cyborgs (socalled "drones") that are assimilated into one group mind. My intuition is the following: Insofar as the Borg form one mind, they do not share an emotion, because they do not satisfy the plurality condition. The assimilation into the Borg collective erases the self-other distinction. The Borg form a collective mind that, if it were to experience emotions, would do so in the same way as an individual does, and not as groups do.

In "Individual and Community", Stein introduces another example: an army unit "grieving over the loss of its leader." (Stein 2000, 134) She states that this case is different from the loss of a personal friend on account of (1) the subject of the experience, (2) the structure of the experience, and (3) the stream of experience of which the singular experience is part. Regarding the subject of the experience, Stein elaborates that, as a member of the group, "I feel it as our grief. ... I grieve as a member of the unit, and the unit grieves within me." (Stein 2000, 134) This statement is familiar from current accounts of shared emotions. However, Stein complicates the picture when she claims that the "we' embraces not only all those who feel the grief as I do, but all those who are included in the unity of the group: even the ones who perhaps do not know of the event, and even the members of the group who lived earlier or will live later." (Stein 2000, 134) I agree with Caminada that the "we" thereby "assumes a highly idealized extension" (Caminada 2015, 553) that is tied to Stein's understanding of the content of the experience - i.e. the loss of the leader - having objective value that demands an appropriate response - i.e. grief. Based on this assumption, Stein (2000,

\footnotetext{
${ }^{22}$ Both examples are based on the experience of World War I, which provided the paradigmatic examples for most work on shared affectivity in early phenomenology. MacIntyre (2006) explicitly addresses the political character of Stein's thought.
} 
137) claims that if one member actualizes the appropriate emotion, then this is sufficient for it to be classed as a communal experience.

In my opinion, this shows that Stein's value realism causes her to fail to distinguish between group-based emotions and shared emotions. As a result, she runs into the problem of "empty-set experiential groups" (Szanto 2015, 514), experiential communities without any (or only one) current member. While it makes sense to allow for group-based emotions that are experienced solely by one individual, the notion of shared emotions should be restricted to cases of actual sharing by a plurality of individuals. Stein's example from the book on empathy makes it clear that a shared emotion requires some form of co-presence of the participants, which allows for mutual empathy leading to a process of integration into a communal subject. Indeed, I take Stein's example to suggest that we need something like a genealogical account of the formation of experiential communities; there is a story to be told about how a plurality of individuals becomes increasingly unified in a way that allows it to experience an emotion together. ${ }^{23}$ In contrast, her example from "Individual and Community" makes it appear as if sharing an emotion is solely a matter of the group members' experiences, regardless of actual interaction. An important difference between the two examples is that the first considers an emerging and transitory group, whereas the second discusses a strongly integrated group with a relatively stable unified evaluative perspective. Even so, Stein's second example fails to distinguish between the case in which one individual experiences an emotion based on the unified evaluative perspective of the group, and the case in which several members of the group experience an emotion together.

\subsubsection{Integration condition}

To repeat my central claim, a shared emotion needs to fulfill the plurality requirement and the integration requirement. In the previous section, I have cashed out the plurality condition in terms of other-awareness. In this section, I will flesh out my suggestion for the integration condition in terms of a sense of togetherness. In the current debate, Schmid has ventured furthest in exploring what it means to experience an emotion together. As I have shown in my discussion of the phenomenological fusion account, Schmid draws on Scheler to distinguish what we might call the ontic (who experiences the feeling) and the phenomenological subject (as who the feeling is experienced) of an experience. Later, he elaborated on his understanding of the phenomenological subject in terms of "plural self-awareness": the subject of a shared emotion is not singular (for me), but plural (for us) (Schmid 2014a, 2014b).

We can turn to the core of Schmid's proposal via Martens and Schlicht's critique: "Schmid's arguments for the strong thesis that collective intentions can be transparent as ours in the same way that individual intentions can are insufficient. If it is to be an awareness, it will have to be one agent's awareness since (a) if it is supposed to be shared by two or more agents, then Schmid's account will ultimately lead into a regress, because it has to explain how this awareness comes to be shared and we are back where we started. Alternatively, (b) if the awareness is supposed to be had by $a$ common subject then Schmid should inform us how we should make sense of the idea

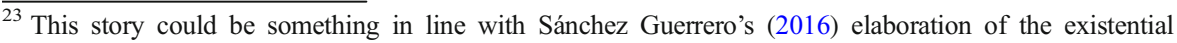
background structures of collective affective intentionality.
} 
that conscious awareness can be a feature of a composite entity and how individuals relate to this group mind and the sense of us pertaining to this group mind. A composite subject simply seems to be the wrong kind of entity when it comes to being the subject of an experience or awareness." (Martens and Schlicht 2017, 12) This critique builds on the inherently complex nature implied by the very notion of the "plural subject": What distinguishes a plural subject from an individual subject is that the former consists of a plurality of the latter. Thus, any plural subject account needs to spell out the relation between the plural subject and the individual subjects that constitute it. Schmid might want to deflect this challenge by emphasizing that according to his understanding of subjectivity, the subject is solely constituted by self-awareness - subjectivity is nothing but non-thematic, prereflective self-awareness - and that the challenge is based on an unwarranted substantializing of the subject. Although I agree with this clarification, I do not think that it completely addresses the original challenge. The question remains: How can we understand that a plurality of individuals has plural self-awareness?

At this point, I suggest considering Stein's solution. Stein developed her thoughts in contrast to Scheler's account. As Scheler is Schmid's main source of inspiration, this allows us to assess how far she agrees with and at what points she diverges from Schmid. Stein agrees that first-person plural givenness is a constitutive part of communal experience; communal experience necessarily involves an "intention toward the communal experience" (Stein 2000, 137), as she puts it. I suggest labeling this the sense of togetherness, an awareness that we are experiencing this emotion together, which amounts to an awareness of the communal subject of the experience.

However, it is imperative for Stein that the communal subject of a communal experience does not imply any merging or fusion at the level of what she - following Husserl - calls the pure ego. Stein insists on the ontological separateness of individual egos: An experience is originarily $^{24}$ given only to the very ego to whom it belongs. This pre-reflective selfawareness - what Zahavi $(2005,2017)$ calls the core or minimal self - cannot be traced to others or the community as its source. In this minimal sense, only individuals have experiences. As a consequence, the communal subject is dependent on individual egos; an experience of the communal subject independent from the experiences of the involved individuals is unfeasible. Moreover, for Stein it is clear that the community has neither prereflective awareness of the experience (Bewußtsein von dem Erleben), nor reflective awareness (Selbstbewußtsein) or reflection (Reflexion): "The community becomes conscious of itself only in us" (Stein 2000, 139), the members. If members are aware of or reflect on what the community experiences, this does not mean that the community becomes aware or reflects; it simply means that the members are aware of or reflect on the experience of the community.

What does this mean in response to Schmid's account of plural self-awareness? I approach this question via Salmela's critique of Schmid. Salmela writes: "True enough, people may pre-reflectively interpret and experience their feelings as your or our, but such experience vanishes as soon as the ontological individual becomes reflexively aware of the feeling as her or his." (Salmela 2012, 38) According to Stein's proposal, it is indeed the case

\footnotetext{
24 "Originarily" (originär) is a technical term in Husserl's phenomenology that refers to the direct access one has to one's own experiences (Husserl 1982, 5). Stein explains this term in On the Problem of Empathy (Stein 1989, 7 f.). In the English edition of Stein's book, "Originarität" is translated as "primordiality", and thereby risks occluding Stein's obvious connection to Husserl.
} 
that only individuals can reflect on their mental lives. However, Salmela is misled in claiming that this means that the interpretation of a feeling as our feeling always vanishes with reflection. For sure, in some cases reflecting on a feeling will reveal that it was mistaken to take it as ours. In the case of a genuinely shared emotion, however, there is no reason why reflection should not confirm the communal subject as the phenomenological subject of the experience. Stein's proposal makes it sensible to say that in shared emotions, there is a communal subject of the experience - that also survives reflection although there is no communal subject that is aware of or reflects on the experience.

\section{Conclusion}

The reconstruction of contemporary approaches to shared emotions in the second section of this paper came to the conclusion that combining concern-based accounts with the main intuition of the phenomenological fusion account is the most promising path towards a multifaceted theory of shared emotions: A shared emotion requires that both the evaluative content and the affective experience are shared. Helm's account of plural agents in terms of a unified evaluative perspective is the most promising candidate for spelling out the sharedness of evaluative content. Stein's notion of a communal subject suggests that we need to complement it with a genealogical account of how individuals become unified into groups that form the basis for the sharing of emotional experiences. Such communal subjects need not be stable and lasting; they can also be transient and fluid, as in Stein's example of the collective joy about victory. For a shared emotion proper, i.e. an emotion that is shared in a stronger sense than individuals having independent emotions based on the evaluative perspective of a group, the affective experience must be shared as well - in other words, we need to experience the concrete emotional episode together. I suggested cashing this out in terms of two requirements: the plurality requirement and the integration requirement.

In the final part, I turned to Edith Stein's phenomenological investigation of communal experience to further elaborate those features of shared emotions. My Steinian proposal regarding the plurality requirement suggests that in a shared emotion, individuals merge into a communal subject, but that such merging does not eliminate individual perspectives, but constitutively involves other-awareness, i.e. an awareness of the plurality of partaking individuals. My Steinian solution to the integration requirement allows us to speak of communal experiences in a strong sense, without necessitating consciousness at the level of the community. Stein suggests that while only individuals can become aware of or reflect on experiences, such reflection can reveal emotions not as mine and yours, but as our emotion, that is, belonging to the communal subject. Following this line of thought, a shared emotion involves a sense of togetherness, i.e. an awareness of the communal subject of the experience, an awareness of "us" as the plural emoter.

Acknowledgements I thank two anonymous referees for their very helpful comments. The research for this article was part of a project funded by Austrian Science Fund (FWF): J-4055. Open access funding was also provided by Austrian Science Fund (FWF).

Open Access This article is distributed under the terms of the Creative Commons Attribution 4.0 International License (http://creativecommons.org/licenses/by/4.0/), which permits unrestricted use, distribution, and 
reproduction in any medium, provided you give appropriate credit to the original author(s) and the source, provide a link to the Creative Commons license, and indicate if changes were made.

\section{References}

Burns, T. (2015). On being a 'we': Edith Stein's contribution to the Internalism debate. Human Studies, 38(4), 529-547.

Calcagno, A. (2014). Lived experience from the inside out: Social and political philosophy in Edith stein. Pittsburgh: Duquesne University Press.

Caminada, E. (2015). Edith Stein's account of communal mind and its limits: A phenomenological reading. Human Studies, 38(4), 549-566.

Connor, S. (2013). Collective emotions: Reasons to feel doubtful. Presented at the the history of emotions annual lecture, Queen Mary, University of London, October 9. stevenconnor.com/collective/collective.pdf.

Damásio, A. R. (1994). Descartes' error: Emotion, reason, and the human brain. New York: Putnam.

Demmerling, Christoph. 2014. "Geteilte Gefühle? Überlegungen Zur Sozialität Des Geistes." In Die Dimensionen Des Sozialen. Neue Philosophische Zugänge Zu Fühlen, Wollen Und Handeln, edited by Karl Mertens and Jörn Müller, 21-39. Berlin: De Gruyter.

Fuchs, T. (2013). Depression, Intercorporeality, and Interaffectivity. Journal of Consciousness Studies, 20(78), 219-238.

Fuchs, T., \& De Jaegher, H. (2009). Enactive Intersubjectivity: Participatory sense-making and mutual incorporation. Phenomenology and the Cognitive Sciences, 8(4), 465-486.

Gilbert, M. (2002). Collective guilt and collective guilt feelings. The Journal of Ethics, 6, 115-143.

Gilbert, M. (2014). How we feel: Understanding everyday collective emotion ascription. In C. Emotions (Ed.), Mikko Salmela and Christian von Scheve (pp. 17-31). Oxford: Oxford University Press.

Goldie, Peter. 2000. The emotions. A Philosophical Exploration. Exford: Clarendon Press.

Hatfield, E., Cacioppo, J. T., \& Rapson, R. L. (1994). Emotional Contagion. Cambridge: Cambridge University Press.

Helm, B. W. (2001). Emotional reason: Deliberation, motivation, and the nature of value. Cambridge: Cambridge University Press.

Helm, B. W. (2002). Felt evaluations. A theory of pleasures and pains. American Philosophical Quarterly, 39, 13-30.

Helm, B. W. (2008). Plural Agents. Nous, 42(1), 17-49.

Helm, B. W. (2009). Emotions as evaluative feelings. Emotion Review, 1, 248-255.

Helm, B. W. (2014). Emotional communities of respect. In C. Emotions (Ed.), Mikko Salmela and Christian von Scheve (pp. 47-60). Oxford: Oxford University Press.

Huebner, B. (2011). Genuinely collective emotions. European Journal for Philosophy of Science, 1(1), 89-118.

Husserl, E. (1982). Ideas Pertaining to a Pure Phenomenology and to a Phenomenological Philosophy: First Book: General Introduction to a Pure Phenomenology. Translated by F. Kersten. Dordrecht: Kluwer.

Jardine, J. (2015). Stein and Honneth on empathy and emotional recognition. Human Studies, 38(4), 567-589.

Kenny, A. (1963). Action, emotion and will. London: Routledge.

Konzelmann Ziv, A. (2007). Collective guilt feeling revisited. Dialectica, 61(3), 467-493.

Krebs, A. (2010). 'Vater Und Mutter Stehen an Der Leiche Eines Geliebten Kindes': Max Scheler Über Das Miteinanderfühlen. Allgemeine Zeitschrift Für Philosophie, 35(1), 9-43.

Krueger, J. (2013). Merleau-Ponty on shared emotions and the joint ownership thesis. Continental Philosophy Review, 46, 509-531.

León, F., Szanto, T., \& Zahavi, D. (2017). Emotional sharing and the extended mind. Synthese. https://doi. org/10.1007/s11229-017-1351-x.

MacIntyre, Alasdair C. 2006. Edith Stein. A Philosophical Prologue 1913-1922. Lanham: Rowman \& Littlefield: Sheed \& Ward.

Martens, J., \& Schlicht, T. (2017). Individualism versus interactionism about social understanding. Phenomenology and the Cognitive Sciences. https://doi.org/10.1007/s11097-017-9499-x.

Merleau-Ponty, M. (2012). Phenomenology of perception. London: Routledge.

Michael, J. (2011). Shared emotions and joint action. Review of Philosophy and Psychology, 2(2), 355-373.

Mühlhoff, R. (2015). Affective resonance and social interaction. Phenomenology and the Cognitive Sciences, 14, 1001-1019.

Prinz, J. J. (2004). Gut reactions: A perceptual theory of emotion. Oxford: Oxford University Press.

Ratcliffe, M. (2008). Feelings of Being. Oxford: Oxford University Press.

Roberts, R. C. (2003). Emotions. An essay in aid of moral psychology. Cambridge: Cambridge University Press. 
Salmela, M. (2012). Shared emotions. Philosophical Explorations, 15(1), 33-46.

Salmela, M., \& Nagatsu, M. (2016). Collective emotions and joint action. Journal of Social Ontology, 2(1), 33-57.

Salmela, M., \& Nagatsu, M. (2017). How does it really feel to act together?: Shared emotions and the phenomenology of we-agency. Phenomenology and the Cognitive Sciences, 16(3), 449-470.

Salmela, M., \& von Scheve, C. (Eds.). (2014). Collective emotions. Oxford: Oxford University Press.

Sánchez Guerrero, H. Andrés. 2011. “Gemeinsamkeitsgefühle Und Mitsorge: Anregungen Zu Einer Alternativen Auffassung Kollektiver Affektiver Intentionalität.” In Affektive Intentionalität. Beiträge Zur Welterschließenden Funktion Der Menschlichen Gefühle, edited by Jan Slaby, Achim Stephan, Henrik Walter, and Sven Walter. Paderborn: mentis.

Sánchez Guerrero, H. Andrés. 2016. Feeling Together and Caring with One Another. A Contribution to the Debate on Collective Affective Intentionality. Cham: Springer.

Scheler, M. (1973). Formalism in ethics and non-formal ethics of values: A new attempt toward the Foundation of an Ethical Personalism. Translated by Manfred S. Frings and Roger L. Funk. Evanston: Northwestern University Press.

Scheler, M. (2008). The Nature of Sympathy. Translated by Peter heath. London: Transaction Publishers.

Scherer, K. R. (2005). What are emotions? And how can they be measured? Social Science Information, 44(4), 695-729.

Schloßberger, Matthias. 2016. "The varieties of togetherness. Scheler on collective affective intentionality." In Social Reality: The Phenomenological Approach to Social Reality. History, Concepts, Problems, edited by Alessandro Salice and Hans Bernhard Schmid, 173-95. Berlin: Springer.

Schmid, Hans Bernhard. 2008. "Shared feelings: Towards a phenomenology of collective affective intentionality." In Concepts of Sharedness: Essays on Collective Intentionality, edited by Hans Bernhard Schmid, Nikolaos Psarros, and Katinka Schulte-Ostermann. Frankfurt am Main: Ontos.

Schmid, H. B. (2009). Plural action. Berlin: Springer.

Schmid, H. B. (2014a). Plural self-awareness. Phenomenology and the Cognitive Sciences, 13, 7-24.

Schmid, H. B. (2014b). The feeling of being a group: Corporate emotions and collective consciousness. In C. Emotions (Ed.), Mikko Salmela and Christian von Scheve (pp. 3-22). Oxford: Oxford University Press.

Schmid, H. B. (2015). Collective emotions - phenomenology, ontology, and ideology. What should we learn from max Scheler's war propaganda. Thaumazein, 3, 103-119.

Schmid, Hans Bernhard. 2016. "Collective emotions." In The Routledge Handbook of Collective Intentionality, edited by Kirk Ludwig and Marija Jankovic. London: Routledge.

Slaby, Jan. 2008. Gefühl Und Weltbezug: Die Menschliche Affektivität Im Kontext Einer NeoExistentialistischen Konzeption von Personalität. Paderborn: mentis.

Slaby, Jan, Achim Stephan, Henrik Walter, and Sven Walter, eds. 2011. Affektive Intentionalität Hintergrundgefühle, Möglichkeitsräume, Handlungsorientierung. Paderborn: mentis.

Smith, A. (2002). The theory of moral sentiments. Cambridge: Cambridge University Press.

Solomon, R. C. (1993). The passions. Emotions and the meaning of life (2nd ed.). Indianapolis: Hackett Publishing.

Stein, E. (1989). On the Problem of Empathy. The collected works of Edith Stein 3. Washington, D.C.: ICS Publications.

Stein, E. (2000). Philosophy of Psychology and the Humanities. The collected works of Edith Stein 7. Washington, D.C.: ICS Publications.

Stern, D. N. (1998). The interpersonal world of the infant: A view from psychoanalysis and Developmental Psychology. London: Karnac Books.

Sugden, R. (2002). Beyond sympathy and empathy: Adam Smith's concept of fellow-feeling. Economics and Philosophy, 18, 63-87.

Szanto, T. (2015). Collective emotions, normativity, and empathy: A Steinian account. Human Studies, 38(4), $503-527$.

Szanto, T. (2016). "Husserl on collective intentionality." In Social Reality: The Phenomenological Approach to Social Reality. History, Concepts, Problems, edited by Alessandro Salice and Hans Bernhard Schmid, 145-72. Berlin: Springer.

Szanto, T., \& Moran, D. (2015a). Introduction: Empathy and collective intentionality - the social philosophy of Edith stein. Human Studies, 38(4), 445-461.

Szanto, T., \& Moran, D. (Eds.) (2015b). Special Issue on Empathy and Collective Intentionality - The Social Philosophy of Edith Stein. In Human Studies, Vol. 38 (4).

Taipale, J. (Ed.). (2015). Empathy and the melodic Unity of the other. Human Studies, 38(4), 463-479.

Vendrell Ferran, I. (2015). Empathy, emotional sharing and feelings in Stein's early work. Human Studies, 38(4), 481-502.

von Scheve, C., \& Ismer, S. (2013). Towards a theory of collective emotions. Emotion Review, 5(4), 1-8. 
Zahavi, D. (2005). Subjectivity and selfhood: Investigating the first-person perspective. Cambridge: MIT Press. Zahavi, D. (2017). Thin, thinner, thinnest: Defining the minimal self. In C. Durt, T. Fuchs, \& C. Tewes (Eds.), Embodiment, Enaction, and culture: Investigating the constitution of the shared world (pp. 193-200). Cambridge: MIT Press. 